\title{
Etude de la composition botanique du régime alimentaire des ruminants domestiques exploitant des parcours agro-pastoraux du Sénégal par analyse histologique des fèces : effets de la technique de conservation et de la centrifugation des fèces
}

\author{
MCB Diallo 1 \\ avec la collaboration technique de B Ahokpé 2 \\ 1 Service d'Alimentation, IEMVT/CIRAD, 10, rue P-Curie, 94704 Maisons-Alfort Cedex, France; \\ 2 LNERVIISRA, BP 2057, Dakar, Sénégal
}

Summary - During a microhistological study of feces from domestic ruminants (cattle, sheep, goats), centrifugation was used to increase from 11 (classic method) to $93 \%$ the rate of dicotyledon epiderms in the total particles of the suspension. Regardless of the conservation method used (drying or addition of salt, formol or ethanol), a better analysis of the dicotyledon part of the diet was obtained.

Introduction - L'étude histologique des fragments épidermiques contenus dans les fèces de bovins, d'ovins et de caprins du Sénégal permet de déterminer la composition botanique de leurs régimes alimentaires. Les préparations microscopiques de fèces prélevées en saison sèche contiennent peu d'épidermes (moins de $30 \%$ des particules) et beaucoup de fibres (jusqu'à $100 \%$ de faisceaux et nervures; Planton, 1989). Nous avons étudié différents modes de conservation des fèces et l'intérêt d'une étape de centrifugation dans la préparation classique des échantillons afin d'améliorer les conditions d'utilisation de cette technique d'analyse.

Matériel et Méthodes - Les fèces proviennent d'un parcours agro-pastoral soudanien. Chaque échantillon de mélange ( 3 à 5 sujets par espèce; $n=3$ ) de fèces est soumis à 4 modes de conservation différents à la température ambiante: séchage au soleil, addition de sel $(\mathrm{NaCl})$, mélange avec de l'acide formique à $20 \%$ ou avec de l'éthanol à $90^{\circ}$. Chaque sous- échantillon $(n=12)$ est traité (homogénéisation, lavage, tamisage, etc; Baumgartner et Martin, 1939) et les particules de 180 à $500 \mu \mathrm{m}$ placées dans une solution aqueuse à gradients discontinus de saccharose (70 et $60 \%$ ) sont centrifugées à $7000 \times \mathrm{g}$ pendant $25 \mathrm{~min}$. La suspension de particules est montée entre lame et lamelle pour toutes les espèces à raison de 5 lames par sous-échantillon. Des lames sont aussi préparées sans centrifugation selon la méthode classique (Baumgartner et Martin, 1939) ainsi qu'à partir du culot de centrifugation pour les bovins afin de comparer la suspension, le culot et la préparation classique pour cette espèce. Les lames sont analysées au microscope photonique $(x 100)$ à raison de 20 champs par lame contenant chacun 3 à 5 fragments (300 à 500 par préparation, Sparks et Malechek, 1968). Les espèces sont déterminées en les comparant avec des épidermes de référence provenant de plantes des stations d'étude.

Les proportions des principales catégories végétales (fibres et épidermes de mono- et de dicotylédones déterminées ou non), sont comparées entre elles par le test de Wilcoxon (Sanders et al, 1984) (tableau I). Les résultats des ovins proches de ceux des caprins ne sont pas rapportés. 
Tableau I. Proportions des principales catégories de particules végétales identifiées dans des fèces de bovins et de caprins conservées à sec (Sc), au sel (Se), au formol (Fo) ou à l'éthanol (Al) et centrifugées (cent; suspension : Su; ou culot : $\mathrm{Cu}$ ) ou non (méthode classique : $\mathrm{Cl}$ ). Effet des traitements sur les contributions spécifiques (\%) des catégories végétales identifiées.

\begin{tabular}{|c|c|c|c|c|c|c|c|c|c|c|c|}
\hline & \multicolumn{7}{|c|}{ Bovin } & \multirow{2}{*}{\multicolumn{4}{|c|}{$\frac{\text { Caprin }}{\text { Cent : Su }}$}} \\
\hline & \multirow[t]{2}{*}{$\mathrm{Cl}$} & $\mathrm{Cu}$ & \multirow[t]{2}{*}{ Su } & \multicolumn{4}{|c|}{ Cent : Su } & & & & \\
\hline & & Se & & $S c$ & Se & Fo & $A l$ & Sc & Se & Fo & $A I$ \\
\hline $\begin{array}{l}\text { Fibres } \\
\text { Epidermes } \\
\text { dicotylédones indéterminées } \\
\text { dicotylédones déterminées } \\
\text { (nombre d'espèces) } \\
\text { monocotylédones indéterminées } \\
\text { indéterminés divers } \\
\text { Différences entre les techniques } \\
\text { de préparation ou de conservationa }\end{array}$ & $\begin{array}{c}72 \\
28 \\
2 \\
9 \\
(11) \\
15 \\
2 \\
\mathrm{Cl} \\
\mathrm{a} \\
\mathrm{Su}\end{array}$ & $\begin{array}{c}84 \\
16 \\
1 \\
6 \\
(7) \\
9 \\
0 \\
S \\
S\end{array}$ & $\begin{array}{c}1 \\
99 \\
19 \\
67 \\
(21) \\
3 \\
10 \\
5\end{array}$ & $\begin{array}{c}2 \\
98 \\
26 \\
62 \\
(23) \\
1 \\
9 \\
\text { Sc } \\
\text { Se } \\
\text { Fo }\end{array}$ & $\begin{array}{c}1 \\
99 \\
19 \\
67 \\
(21) \\
3 \\
10 \\
\text { NS }\end{array}$ & $\begin{array}{c}10 \\
90 \\
15 \\
62 \\
(17) \\
3 \\
10 \\
\text { S } \\
\text { NS }\end{array}$ & $\begin{array}{c}3 \\
97 \\
16 \\
69 \\
(20) \\
1 \\
11 \\
\text { NS } \\
\text { NS } \\
\text { NS }\end{array}$ & $\begin{array}{c}0 \\
100 \\
14 \\
68 \\
(15) \\
0 \\
18 \\
\text { Sc } \\
\text { Se } \\
\text { Fo }\end{array}$ & $\begin{array}{r}0 \\
100 \\
7 \\
78 \\
(15) \\
0 \\
15 \\
\text { NS }\end{array}$ & $\begin{array}{r}0 \\
100 \\
10 \\
76 \\
(16) \\
0 \\
14 \\
\text { NS } \\
\text { NS }\end{array}$ & $\begin{array}{r}0 \\
100 \\
15 \\
72 \\
(15) \\
0 \\
13 \\
\text { NS } \\
\text { NS } \\
\text { NS }\end{array}$ \\
\hline
\end{tabular}

a Test bilatéral de Wilcoxon $(\alpha=0,05) \cdot S=$ significatif; NS $=$ non significatif.

Résultats et Discussion - Le taux d'épidermes (proportion de fragments d'épidermes sur le nombre total de particules considérées) est significativement différent suivant la méthode de préparation des lames : il est plus grand dans la suspension de centrifugation ( $99 \%$ des particules) que dans la préparation classique $(28 \%)$ et que dans le culot de centrifugation $(16 \%)$. La centrifugation permet donc de séparer les fibres des épidermes quels que soient l'espèce animale et le mode de conservation. Les suspensions contiennent principalement des épidermes de dicotylédones, ceux des monocotylédones se concentrant dans le culot de centrifugation. Ces derniers de taille très réduite (non mesurée), quelle que soit la méthode de conservation ou de préparation, ne sont pas identifiables, probablement en raison de l'état "pailleux" des graminées qui les rend fragiles et cassants; cette hypothèse pourra être vérifiée par l'étude de matériel récolté en saison des pluies. Suivant les échantillons, on a déterminé 15 à 23 espèces de dicotylédones qui représentent 62 à $81 \%$ des fragments végétaux contenus dans les suspensions. Les pourcentages des différentes espèces végétales varient peu en fonction du mode de conservation. D'un point de vue pratique, le séchage est la méthode la plus contraignante (temps) et le salage la plus simple.

En conclusion, une étape de centrifugation ajoutée à la procédure classique de préparation des fèces récoltées en saison sèche en vue de leur étude histologique permet la concentration des épidermes de dicotylédones et entraîne l'élimination de ceux des monocotylédones avec les fibres. La fraction du régime constituée de dicotylédones peut ainsi être étudiée avec plus de facilité et de précision. Un simple salage suffit à la conservation des échantillons.

Baumgartner LL, Martin AC (1939) J Wild Manage $3,266-268$

Planton H (1989) Rev Elev Méd Vét Pays Trop 42, 245-252

Sanders DH, Murph AF, Eng RJ (1984) Les statistiques. Une approche nouvelle. McGrawHill, Quebec, 453

Sparks DR, Malechek JC (1968) J Range Manage 21, 204-205 